\title{
A Case Study on Applying ITIL Availability Management Best Practice
}

\author{
Jihong Zeng \\ New York Institute of Technology \\ E-Mail: jzeng@nyit.edu
}

\begin{abstract}
This paper presents a case study on how to apply ITIL availability management best practice to assess the end-to-end service availability in a tiered web service delivery environment. It also helps pinpoint the road blocks to the required service level and provide cost-effective solution for improved service delivery. An overview of basic ITIL availability management concept is provided along with the introduction to two key parameters, mean time between failure (MTBF) for reliability and mean time to repair (MTTR) for maintainability. Then a block diagram modeling approach for the overall information system availability assessment is presented. The block diagrams are used to describe the interrelationship among the components or subsystems to define a system model. The ITIL best practice approaches for availability management are discussed in detail in the case study. It demonstrates that the overall service availability is affected by the availability of information systems as well as applications and operational processes. The modeling approach is capable of gaining visibility on root cause of the service availability degradation, identifying risks in the existing information system, and providing support to future application development and infrastructure upgrade for high availability business services.
\end{abstract}

Keywords: Service Availability, Information System Availability, ITIL, Availability Modeling 


\section{INTRODUCTION}

Over the years, organizations are becoming increasingly dependent on IT to fulfill their corporate objectives. This has resulted in a growing demand for IT services to meet the customers' requirements and expectations. Service availability has become one of the most important aspects of service delivery in the highly competitive e-business economy. Moreover, service availability has dramatic impact on customer satisfaction and corporate reputation as customers are just a mouse click away from competitor's offerings (Fisher, 2000). A lot of effort and improvement have been made to ensure high availability in each technology industry (Potegieter et al., 2005). However, risks to service availability may be caused by technology, process as well as human error throughout the whole IT infrastructure and within every management process (Pope, 1986). There is not enough research and focus given on understanding and improving the overall end-to-end IT service availability from end-user's perspective (Hochstein et al., 2005). Without visibility into the overall availability of underlying service delivery components including information systems, applications and operational processes, it is impossible to make informed business decisions about IT resources investment to provide cost-effective solution to address the service level requirements from customers.

\section{ITIL AND SERVICE AVAILABILITY}

\section{Background}

The Information Technology Infrastructure Library (ITIL) was originally developed by British Office of Government Commerce (OGC, 2000) as a framework of best practice approaches intended to facilitate the delivery of high-quality IT services (van Bon et al., 2002). ITIL outlines an extensive set of management procedures that are intended to support business in achieving both quality and value for money in IT operations (van Bon, 2002). However, there has been limited academic research about ITIL despite of the increasingly upsurge in awareness and adoption of ITIL by IT practitioners (Hochstein et al., 2005; Potgierer et al., 2005; Computer Economics, 2005).

ITIL best practice on availability management is to ensure that service-affecting incidents do not occur, or that timely and effective action is taken when they do occur. The concept of availability is related to reliability and maintainability (van Bon et al., 2002).

Nickel's work (1978) introduced key concept of availability and proposed a logarithmic probability function for measuring availability. Mean Time Between Failure 
(MTBF), is the average time between failures of a component. For instance, MTBF for hardware component can be obtained from hardware vendor based on its configuration. Mean Time To Repair (MTTR), is the time taken to repair a failed module (Zacks, 1992). For instance, repair generally means replacing the hardware component in an operational environment. Thus hardware MTTR could be viewed as mean time to replace a failed hardware module.

Availability is the percentage of time when a system is operational. Availability of a component can be obtained by the formula (Nickel, 1978; Zacks, 1992):

$$
\text { Availability }=\frac{M T B F}{M T B F+M T T R}
$$

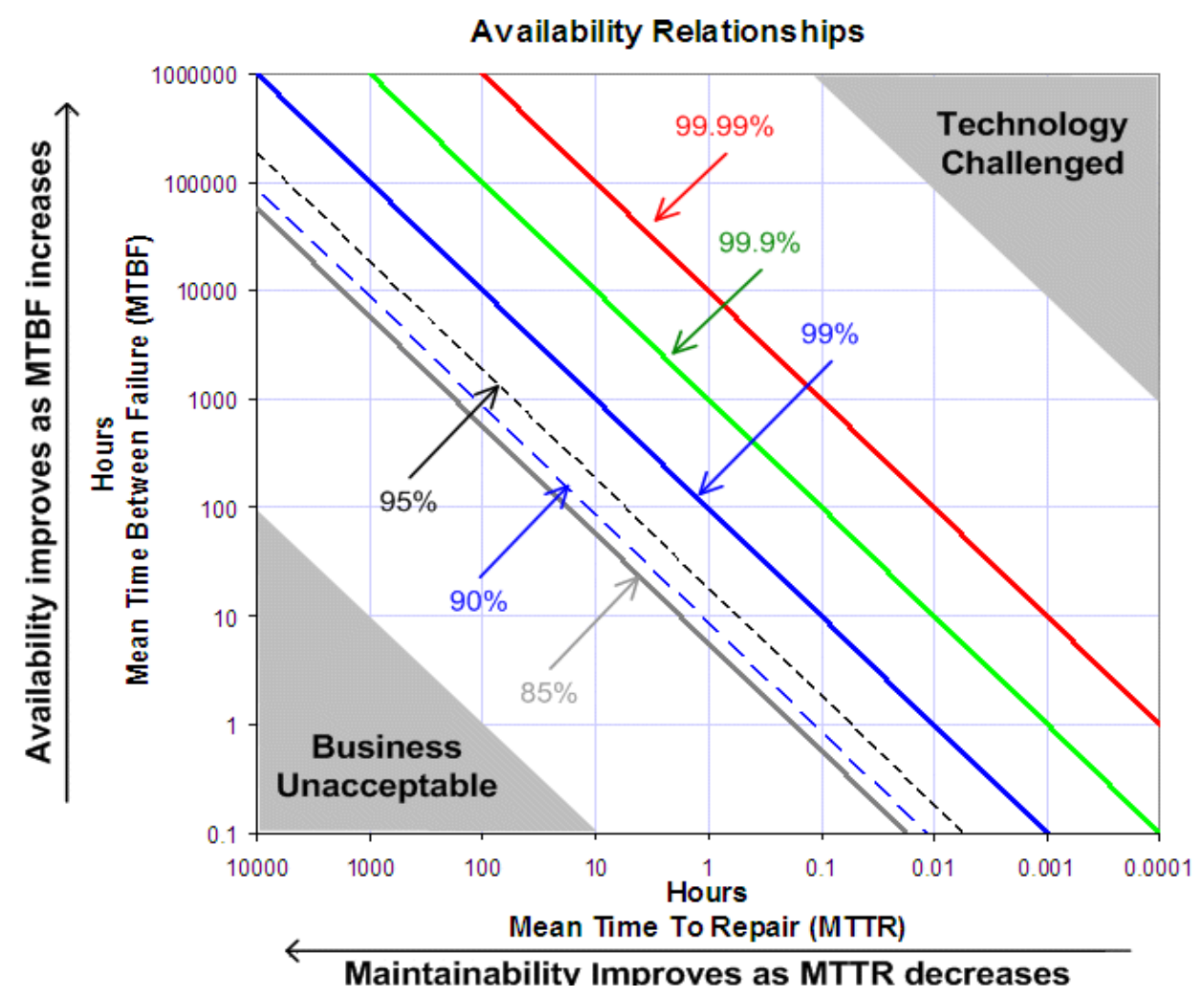

Figure 1 Relationship between availability, MTBF, and MTTR

\section{Business Requirement for Availability}

Based on the above formula, high availability would be expected if mean time between failures (MTBF) is very large compared to the mean time to repair (MTTR). 
Likewise if mean time to repair is decreased, availability will be higher. As system reliability decreases (MTBF decreases), better maintainability (such as shorter MTTR) is needed to sustain the same level of availability. Figure 1 illustrates the relationship between MTBF and MTTR. It is worth noticing that the business demands high availability with high MTBF and low MTTR at the same time. Therefore, those shaded areas in the diagram represent the regimes that are either technical challenged or unacceptable by business.

\section{BLOCK DIAGRAM MODELING APPROACH}

In this study, block diagrams are used to describe the relationship between the service delivery components and to define a system model. When used in this fashion, a block diagram is then referred to as reliability block diagram (RBD) (Raghavendra and Makam, 1986).

A reliability block diagram is a graphical representation of the system components and how they are reliability-wise related. This may differ from how the components are physically connected. RBDs are constructed out of blocks. The blocks are connected with direction lines that represent the reliability relationship between the blocks. A block is usually represented in the diagram by a rectangle. In the reliability block diagram, such blocks represent the component, subsystem at its chosen black box level (Bowles and Dobbins, 1998). The overall system availability is calculated by modeling the system as an interconnection of parts in serial and/or parallel (Nickel, 1978; Hoyland and Rausand, 1994).

\section{Availability of Serial Components}

As an example, two components, $\mathrm{X}$ and $\mathrm{Y}$, are considered to be operating in serial if failure of either component results in failure of the combination. The combined system is operational only if both $\mathrm{X}$ and $\mathrm{Y}$ are available. The combined availability is given by: $A_{S}=A_{X} * A_{Y}$ (Nickel, 1978). This implies that the combined availability of a system of two components in serial is always lower than the availability of its individual components. It is clear that even though a very high availability of component $Y$ may be possibly achieved, the overall availability of the system can be dragged down by the low availability of component $X$. This just proves the saying that a chain is as strong as the weakest link. More specifically, a chain could be weaker than the weakest link. 


\section{Availability of Parallel Components}

Two components, $\mathrm{X}$ and $\mathrm{Y}$, are considered to be operating in parallel if the combination is considered failure when both components fail. The combined system is operational if either $\mathrm{X}$ or $\mathrm{Y}$ is available. The combined availability is given by: $\mathrm{A}_{\mathrm{S}}=1-$ $\left(1-A_{X}\right) *\left(1-A_{Y}\right)($ Nickel, 1978). This implies that the combined availability of two components in parallel is always higher than the availability of its individual components. Therefore, parallel operation provides a very powerful mechanism for making a highly reliable system using components with less restriction on reliability. For example, mission-critical systems are designed with redundant components.

\section{Availability Importance}

Availability importance evaluation is frequently used for ranking the components of a system with respect to their contribution to the considered measure of risk, unavailability or unreliability. The importance of a component depends on two factors: the configuration of the component in the system (serial or parallel), and the availability of the component (Hoyland and Rausand, 1994). The following is an example of determining the effective solution to improve the overall system availability using the availability importance.

In this three-component serial system, the overall system availability is equal to product of the availability of three components $\left(A_{S}=A_{A} * A_{B} * A_{C}\right)$.

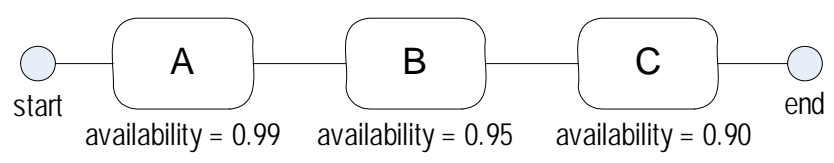

The availability importance of component $\mathrm{i}$ is calculated by $\mathrm{I}_{\mathrm{Ai}}=\partial \mathrm{A}_{\mathrm{S}} / \partial \mathrm{A}_{\mathrm{i}}$ (Leemis, 1995). As shown in Figure 2, component $C$ is more critical to the overall system availability since it has the least availability in this example of serial configuration.

Figure 3 indicates that improving availability of component $\mathrm{C}$ has more substantial impact to the overall system availability. This method helps determine the most costeffective strategy to enhance the overall system availability. 


\section{Component Reliability Importance}

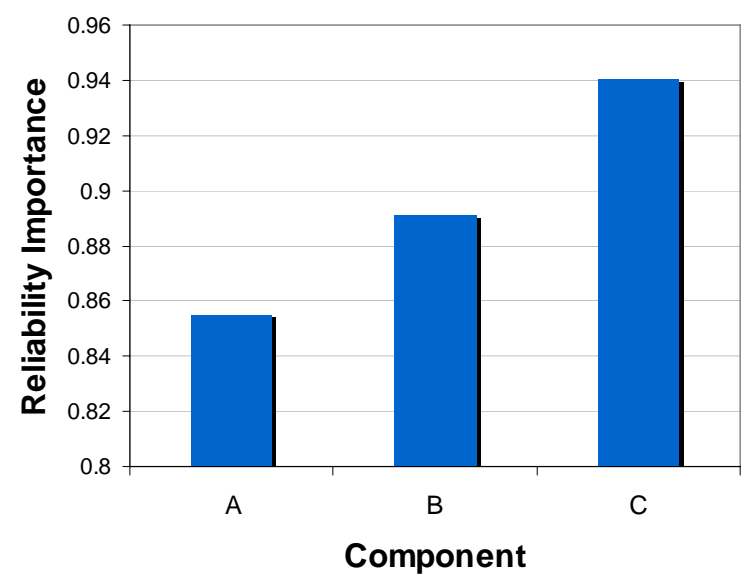

Figure 2 Individual component availability importance

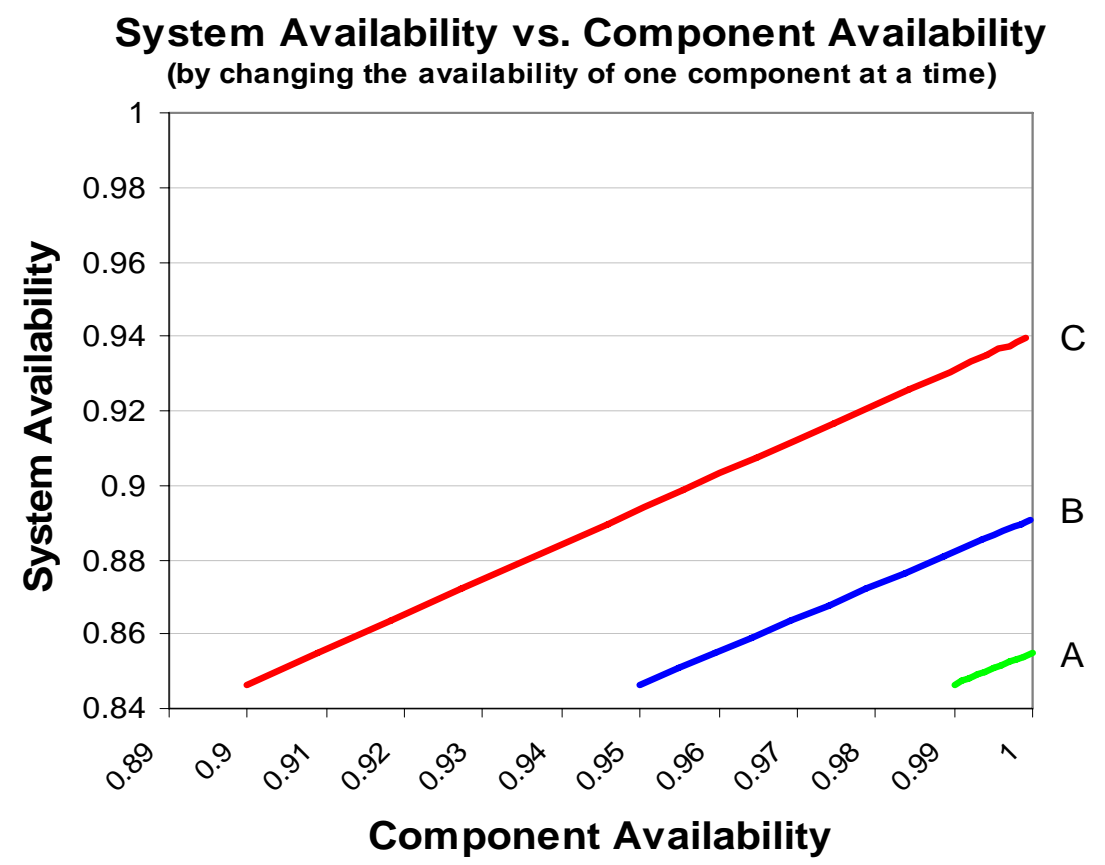

Figure 3 Impact of improving component availability on overall system availability 


\section{A CASE STUDY}

\section{The Modeling Methodology}

A real-world case study was conducted based on the IT infrastructure and the business requirement of a market data service company. In order to provide high quality of service, the company executive management set a target goal of $99.8 \%$ service availability to its customers. The service was delivered by a typical tiered web hosting environment. To help management understand if the current IT infrastructure, applications and operations are capable to support the business goal, a modeling approach was deployed. The availability of web service depends on the availability of the impacting factors such as IT infrastructure, applications, operational processes and people (Murphy and Gent, 1995). Starting with IT infrastructure, the systems are decomposed into sub-system components. To provide quantitative analysis on the IT system availability, the following modeling methodology is deployed to evaluate the overall system availability:

$$
A_{\text {web service }}=A_{\text {networking }} \times A_{\text {web / application server }} \times A_{\text {databa seserver }}
$$

The availability of each sub-system component was assessed. The unreliable subsystem components were identified using the availability importance.

\section{The Modeling Tool}

BlockSim from ReliaSoft (http://www.reliasoft.com) was used during this case study. BlockSim is a modeling tool that provides a visual interface for reliability block diagram creation. Simple drag and drop techniques allow users to build reliability block diagrams (RBDs) for the systems. Configuration options include series, parallel, load sharing and standby redundancy. BlockSim has built-in functions to calculate the overall system availability and help determine the most cost-effective system availability improvement strategy (ReliaSoft Publishing, 2003).

\section{Approach and Key Inputs}

In this case study, the modeling assessment involved a multi-step approach. The first step was to collect system and network setup information, which included collecting both detailed system configuration and networking connection information (Figure 4). Next, availability metrics including MTBF and MTTR were collected. Specifically, the MTBF data were collected from the vendors and the MTTR were collected from either 
the vendors or service contractors. In the next step, relationship block diagram was created using BlockSim. As a result, individual components were created and connected with each other based on their relationships. Then the collected availability data of each component were entered in BlockSim. Finally, the overall system availability was calculated using the BlockSim built-in calculation tool.

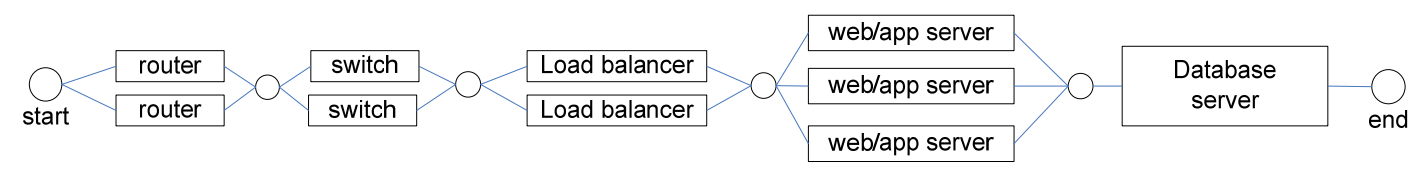

Figure 4 Relationship block diagram of IT systems for service delivery

Figure 5 demonstrates a screenshot of BlockSim user interface with the simulated IT infrastructure systems for the web service delivery.

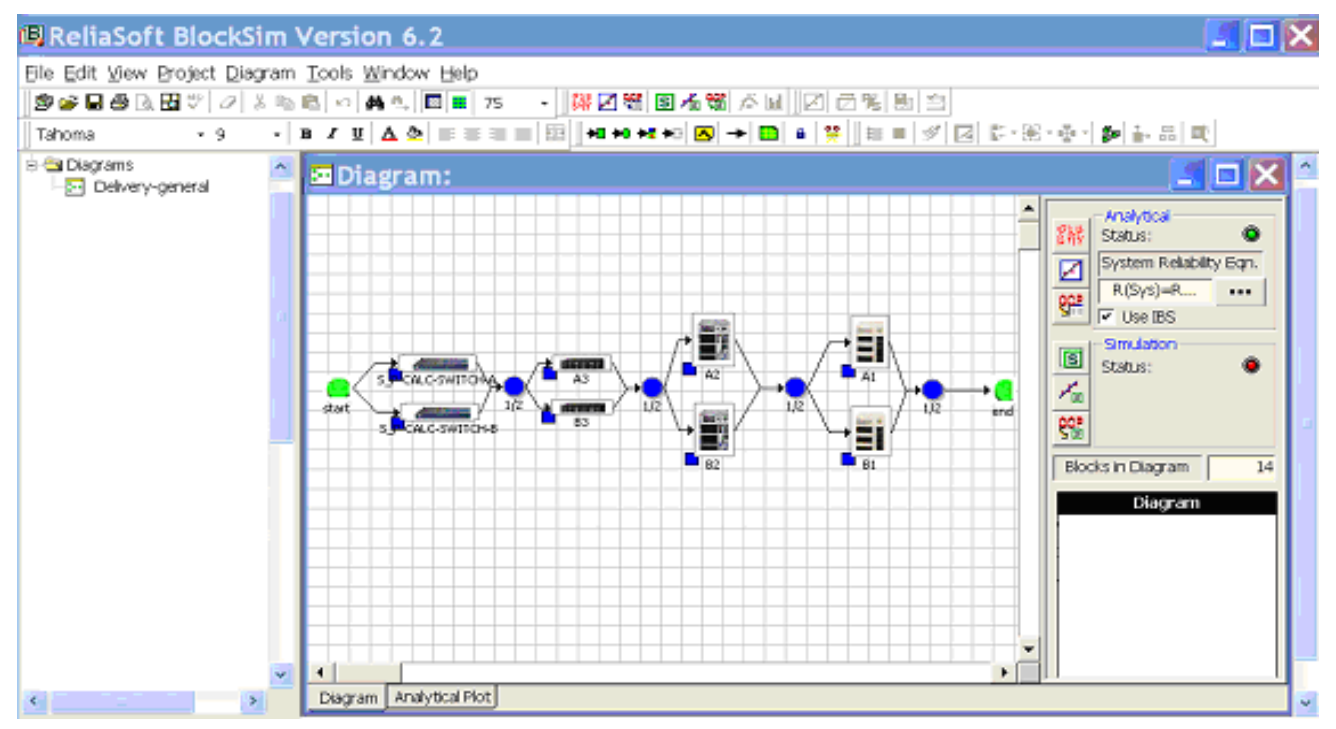

Figure 5 Screenshot of BlockSim user interface

Based on the hardware system reliability specification, Figure 6 illustrates the availability of each sub-system component as well as the overall system availability. It is shown that even though network connectivity is highly available $(99.9973 \%)$, the overall system availability is only $99.6007 \%$ due to the limitation by database servers. Therefore, it is most effective to enhance the database servers in order to improve the overall system availability. 


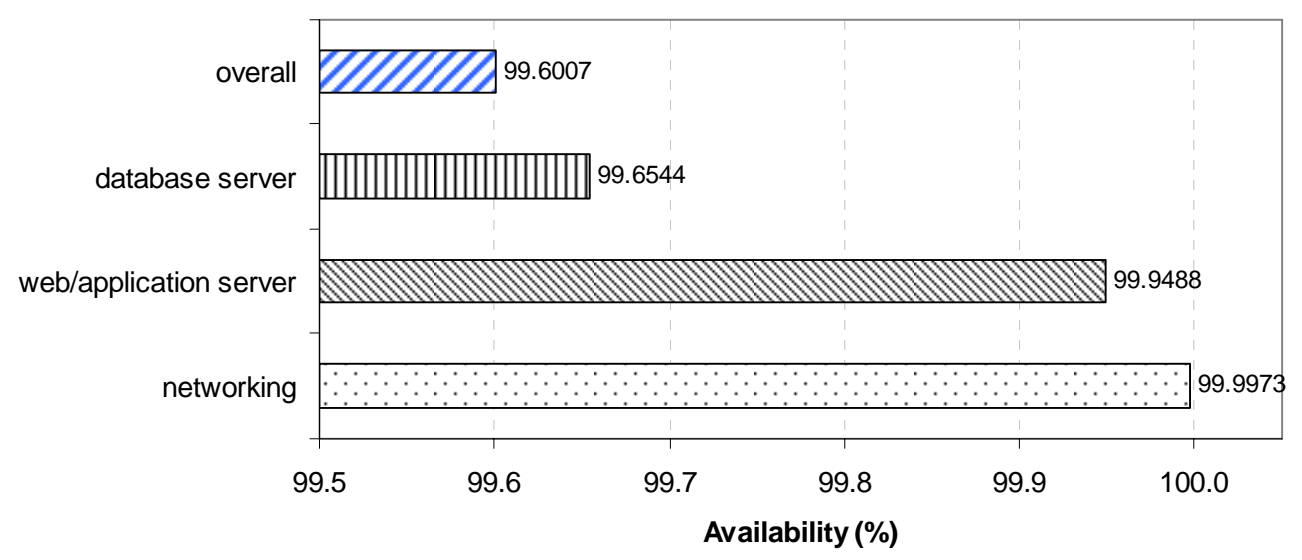

Figure 6 Overall system availability and sub-system component availability

The actual service availability metrics were obtained by analyzing the application performance logs and service helpdesk troubleshoot ticket logs. Figure 7 indicates that the service availability is only $80 \%$ at best from two different measures. "Anecdote Weekly" is an anecdotal report from an interview. "Operations Log" is an analysis of the Operations Log spreadsheet. Service level agreement (SLA) incidents during the 14-week time period of the log, yields an $80 \%$ availability. Five different "goals" are represented to indicate the resultant availability when one incident occurs over five different time periods.

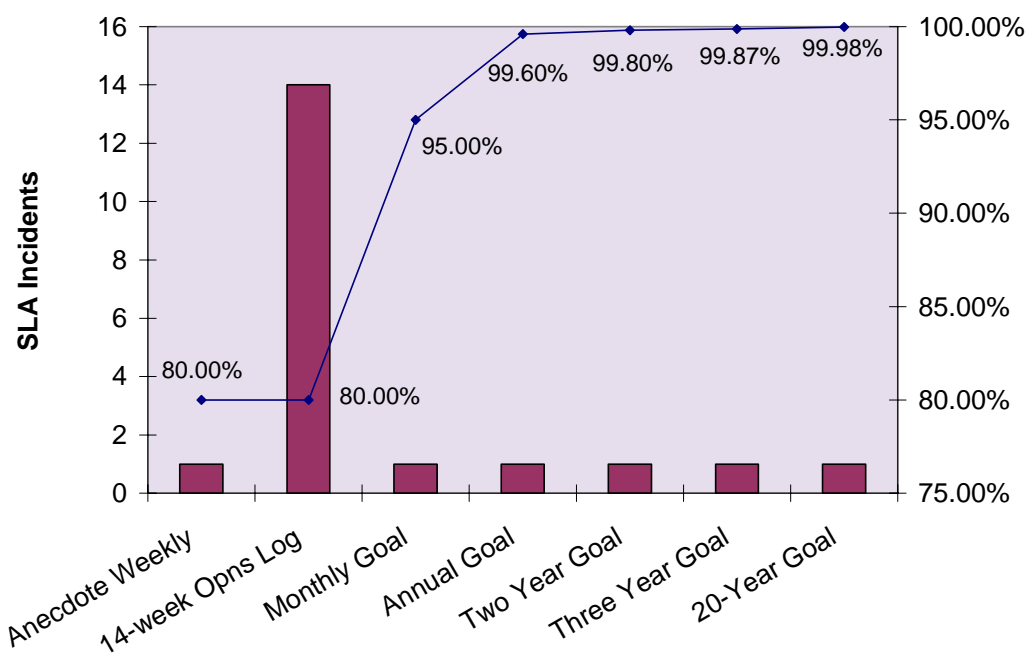

Figure 7 Service availability history from operation logs 


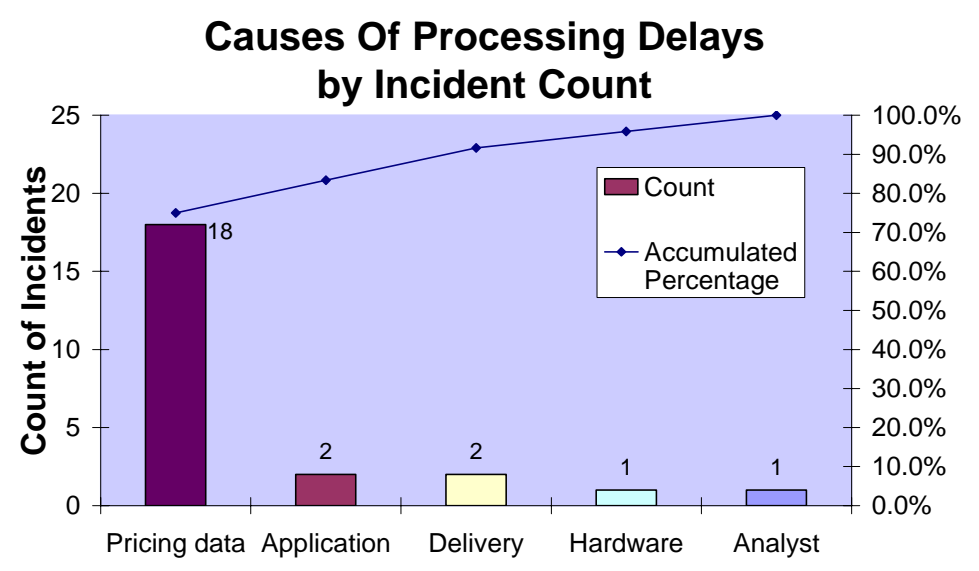

Figure 8 Service impacting incidents by types

The metrics indicated that although a lot of effort is spent on improving availability of infrastructure, the weakest link in the service delivery chain is the operational processes. Causes for all service impacting incidents are shown by the Pareto chart in Figure 8. An apparent problematic area is pricing data, which accounts for almost twothirds of all incidents.

Quality of service depends not only on IT infrastructure but also on applications and operations. A high quality IT infrastructure is only a part of the equation for delivering IT service with high availability. The analysis built a business case for operation excellence in change management, incident management, and release management in order to achieve service availability target set by the management. The executive management team was recommended to initiate an IT service management program throughout the enterprise. ITIL provides a framework for the company to define the organizational structure and skill requirements of an IT organization and a set of standard operational management procedures, which allow the organization to manage the IT operation and associated IT infrastructure. The operational procedures are supplier independent and applicable to all aspects of the IT Infrastructure. IT service management is a top-down, business-driven approach to the IT management. It specifically addresses the strategic business value of IT and the need to deliver a high-quality IT service (van Bon et al., 2002). 


\section{IMPLICATIONS AND CONCLUSION}

This study presents a holistic approach to apply ITIL availability management best practice to evaluate and improve service availability. In addition, it also illustrates that other operational processes and counter measures, such as carefully designed testing, release procedures and appropriate staff training plans, can be employed to help mitigate risks in the service delivery chain. IT service availability management is to ensure that all areas of risk to service availability are taken into account and that the overall IT infrastructure and the maturity of management process are sufficient. The case study demonstrates the capability of applying this holistic approach to help IT managers gain visibility on root cause analysis of the service availability and risks of the existing IT infrastructure, as well as to provide support to future application development and infrastructure design in a high availability environment for e-business.

\section{REFERENCES}

Bowles, J.B., and Dobbins, J. G. (1998). High-Availability Transaction Processing: Practical Experience in Availability Modeling and Analysis. Proceedings of the 1999 Annual Reliability and Maintainability Symposium, 1(1), 268-273.

Computer Economics. (2005). ITIL Adoption: 2006 could be a watershed year in U.S.

Retrieved 2007, from http://www.computereconomics.com/article.cfm?id=1068.

Fisher, S. (2000). E-business Redefines Infrastructure Needs. InfoWorld, 22(2), 22.

Hochstein, A., Tamm, G. and Brenner, W. (2005). Service-oriented IT management:

Benefit, Cost and Success Factors. Regensburg, Germany: Proceedings of European Conference on Information Systems.

Hoyland, A., and Rausand, M. (1994). System Reliability Theory: Models and Statistics Methods. New York: Wiley.

Leemis, L.M. (1995). Reliability-Probabilistic Models and Statistical Methods, Englewood Cliffs. New Jersey: Prentice Hall.

Murphy B., and Gent, T. (1995). Measuring System and Software Reliability Using an Automated Data Collection Process. Quality and Reliability Engineering International, 11, 341-353.

Nickel, S.J. (1978). The Investment Decisions of Firms. Cambridge: University Press.

Office of Government Commerce (2000). IT Infrastructure Library. The Stationary Office: London.

Pope, R. H. (1986). Human Performance: What Improvement from Human Reliability 
Assessment, Reliability Data Collection and Use in Risk and Availability Assessment. In H.J. Wingender (Ed.), Proceedings of the 5th EuroData Conference (pp. 455-465). New York: Springer-Verlag.

Potgieter, B. C., Botha, J. H., and Lew, C. (2005). Evidence That Use of the ITIL Framework is Effective. Tauranga, New Zealand: Proceeding of the 18th Annual Conference of the National Advisory Committee on Computing Qualifications.

Raghavendra, C. S., and Makam, S. V. (1986). Reliability Modeling and Analysis of Computing Networks.IEEE Transactions on Reliability, 35(2), 156-160.

ReliaSoft Publishing (2003). System Analysis Reference, Reliability, Availability and Optimization. Tucson, AZ: ReliaSoft Publishing.

Van Bon, J. (2002). IT Service Management Guide, Vol. 1, New York: Addison-Wesley.

Van Bon, J., Kemmerling, G., and Pondman, D. (2002). IT Service Management, an Introduction, San Antonio. TX: Van Haren Publishing.

Zacks, S. (1992). Introduction to Reliability Analysis: Probability Models and Statistics Methods. New York: Springer-Verlag. 